\title{
Rescuer's performance during six minutes of chest compressions in a simulated scenario
}

\author{
Desempenho do reanimador durante seis minutos de compressões torácicas realizadas em \\ ambiente simulado \\ Desempeńo del reanimador durante seis minutos de compresiones torácicas realizadas en \\ un entorno simulado
}

Leonel São Romão Preto*; André Filipe Morais Pinto Novo**; Maria Eugénia Rodrigues Mendes***;

Ana Fernanda Ribeiro Azevedo****

\begin{abstract}
Background: The performance of quality chest compressions according to the international guidelines affects the outcomes and survival in cardiac arrest.

Objectives: To analyze the influence of fatigue and physical fitness on the rescuer's performance during a period of 6 minutes of continuous chest compressions.

Methodology: Descriptive-correlational study, with a sample of 38 professionals experienced in resuscitation. Fatigue was assessed through capillary blood lactate levels; physical fitness through strength tests and body composition; and the rescuer's performance through the percentage of correct compressions per minute, which were performed in manikin.

Results: The percentage of correct compressions decreased every minute $(p<.05)$. The lactate levels increased from a baseline value of $1.7 \pm .7 \mathrm{mmol} / \mathrm{L}$ to $5.4 \pm 1.5 \mathrm{mmol} / \mathrm{L}$, and remained high after 20 minutes of rest. Grip strength, and muscle strength and mass of the trunk and upper limbs were positively correlated with the percentage of correct chest compressions.

Conclusion: The body mass index and the physical fitness components - muscle strength and mass - were the variables that best explained the quality of the heart massage over time.
\end{abstract}

Keywords: fatigue; physical fitness; heart massage; cardiopulmonary resuscitation; patient simulation

\section{Resumo}

Enquadramento: As compressões torácicas realizadas com qualidade e segundo as diretrizes internacionais influenciam os resultados e a sobrevida na paragem cardíaca.

Objetivos: Analisar a influência da fadiga e da aptidão física no desempenho do reanimador durante 6 minutos de compressões torácicas contínuas.

Metodologia: Estudo descritivo-correlacional, envolvendo 38 profissionais experientes em reanimação. A fadiga foi avaliada através do nível de lactato capilar, a aptidão física através de testes de força e composição corporal e o desempenho do reanimador pela percentagem correta de compressões por minuto, realizadas em manequim.

Resultados: A percentagem de compressões corretas decresceu minuto a minuto $(\mathrm{p}<0,05)$. O lactato subiu de um valor basal de $1,7 \pm 0,7 \mathrm{mmol} / \mathrm{L}$ para $5,4 \pm 1,5 \mathrm{mmol} / \mathrm{L}$, mantendo-se elevado após 20 minutos de repouso. A força manual e a força e massa muscular do tronco e membros superiores correlacionaram-se positivamente com a percentagem de compressões corretas efetuadas.

Conclusão: O índice de massa corporal e as componentes de aptidão física, força e massa muscular foram as variáveis que melhor explicaram a qualidade da massagem ao longo do tempo.

Palavras-chave: fadiga; aptidão física; massagem cardíaca; ressuscitação cardiopulmonar; simulação de paciente

\footnotetext{
* Ph.D., Coordinating Professor, School of Health, Polytechnic Institute of Bragança, 5300-253, Bragança, Portugal [leonelpreto@ipb.pt]. Contribution to the article: Data treatment, analysis and discussion; article writing. Address for correspondence: Vale Chorido, Rua Senhor dos Perdidos, discussion; article writing. Address for
Lote 101, 5300-392, Bragança, Portugal.

** Ph.D., Adjunct Professor, School of Health, Polytechnic Institute of Bragança, 5300-253, Bragança, Portugal [andre@ipb.pt]. Contribution to the article: Data collection; literature search; revision. **** MSc., Adjunct Professor, School of Health, Polytechnic Institute of Bragança, 5300-253, Bragança, Portugal [maria.mendes@ipb.pt].Contribution to the article: Data collection; literature search; revision. ***** MSc., Adjunct Professor, School of Health, Polytechnic Institute of Bragança, 5300-253, Bragança, Portugal [anitaazevedo@ipb.pt]. Contribution to the article: Data collection.
}

\section{Resumen}

Marco contextual: Las compresiones torácicas realizadas con calidad y según las directrices internacionales influyen en los resultados y la supervivencia del paro cardíaco.

Objetivos: Analizar la influencia de la fatiga y la aptitud física en el desempeño del reanimador durante 6 minutos de compresiones torácicas continuas.

Metodología: Estudio descriptivo y correlacional que incluyó a 38 profesionales experimentados en reanimación. La fatiga fue evaluada por el nivel del lactato capilar, la aptitud física a través de pruebas de fuerza y composición corporal y el desempeño del reanimador por el porcentaje de compresiones correctas por minuto realizadas en un maniquí.

Resultados: El porcentaje de compresiones correctas disminuyó minuto a minuto $(\mathrm{p}<0,05)$. El lactato aumentó de un valor basal de $1,7 \pm 0,7 \mathrm{mmol} / \mathrm{L} \mathrm{a} 5,4 \pm 1,5 \mathrm{mmol} / \mathrm{L}$, permaneciendo elevado después de 20 minutos de reposo. La fuerza manual, así como la fuerza y la masa muscular del tronco y brazos se correlacionaron positivamente con el porcentaje de compresiones correctas realizadas.

Conclusión: El índice de masa corporal y los componentes de aptitud física, fuerza y masa muscular fueron las variables que mejor explicaron la calidad del masaje a lo largo del tiempo.

Palabras clave: fatiga; aptitud física; masaje cardíaco; resucitación cardiopulmonar; simulación de paciente

Received for publication: 08.10 .15

Accepted for publication: 25.01 .16 


\section{Introduction}

In 2013, in the United States of America, there were around 359000 out-of-hospital cardiac arrests (OHCAs), and the survival rate was only $9.5 \%$. In the same year, 209000 people were treated for in-hospital cardiac arrest with a survival rate of 23.9\% (Go et al., 2013). In Portugal, the out-of-hospital emergency services have treated around 4805 patients for cardiac arrests per year between 2007 and 2012 (Ramos, Ascenção, \& Oliveira, 2013). A systematic review of 67 studies reported that OHCAs affect 20 to 140 individuals per 100000 inhabitants worldwide, with survival rates between 2\% and 11\% (Berdowski, Berg, Tijssen, \& Koster, 2010).

In adult OHCAs, the evidence suggests that the outcome of cardiopulmonary resuscitation (CPR) is influenced by variables such as the call for a medical emergency team, the performance of basic life support (BLS), and early defibrillation, when indicated (Nolan et al., 2010). During CPR, the quality of chest compressions is one of the main requirements for an effective defibrillation (Yang et al., 2014). The most recent guidelines of the European Resuscitation Council (ERC) highlight quality chest compressions with a depth of at least $5 \mathrm{~cm}$ and a rate of at least 100 compressions per minute (Nolan et al., 2010). In addition, the guidelines recommend that all rescuers, trained or not, should provide chest compressions to victims of cardiac arrest. In advanced life support (ALS), when an endotracheal tube is placed, chest compressions should be continuous, at a rate of 100 compressions per minute (Nolan et al., 2010).

The greater depth of the compressions recommended by the new guidelines increases the rescuer's fatigue, which may influence the quality of the heart massage (Yang et al., 2014). This study analyzes if the rescuer's performance during a period of 6 minutes of continuous chest compressions, in a simulated scenario, is influenced by fatigue and physical fitness. We designed a descriptive-correlational study with a sample of professionals experienced in resuscitation with the purpose of characterizing the participants according to sociodemographic and anthropometric variables, analyzing the fatigue caused by 6 minutes of chest compressions and its impact on the quality of the heart massage, and assessing physical fitness through strength tests and body composition. Furthermore, we analyzed the correlation between these variables and the percentage of correct compressions performed per minute.

\section{Background}

The first successful and well-documented CPR using external chest compressions in human beings was performed in 1891 by Friedrich Maass (Taw, 1991). At the time, the technique was described as consisting in applying forceful pressure in the chest at a fast speed (Taw, 1991). The cardiac pump/thoracic pump effect caused by compressions has been increasingly highlighted in international guidelines, which recommend rescuer changeover at every 2 minutes to prevent fatigue and optimize circulation (Nolan et al., 2010). A good performance in chest compressions is obtained through the positioning of the victim in a flat surface, the correct placement of the hands on the landmark, a steady compression and release maneuver with equal duration, at a rate of $100 / \mathrm{min}$ (not exceeding 120/min), and a depression of the sternum of at least $5 \mathrm{~cm}$ (Nolan et al., 2010).

In 1998, Ochoa, Ramalle-Gómara, Lisa, and Saralegui described a simulation study with a sample of 38 experienced rescuers. The study found that there is a significant reduction in the percentage of correct compressions over the 5-minute period under analysis, which the authors attributed to fatigue (Ochoa et al., 1998). More recently, new studies have corroborated that the quality of chest compressions decreases significantly over time (Hasegawa, Daikoku, Saito, \& Saito, 2014; Ock, Kim, Chung, \& Kim, 2011; Otsuka et al., 2014).

Fatigue is a topic acknowledged in the international guidelines, with rescuer's exhaustion being one of the reasons for chest compression interruption (Nolan et al., 2010). Aerobic exercise is assumed as ending at the point of exhaustion, and fatigued individuals are not able to produce the muscle strength necessary for the task. Considering fatigue as extreme tiredness or exhaustion caused by an intense or repeating work with an impact on the maximum muscle strength, fatigue levels are not measured in many studies (Bjørshol, Sunde, Myklebust, Assmus, \& Søreide, 2011; Nishiyama et al., 2010; Ochoa et al., 1998; Shin et al., 2014). Other studies assess fatigue based on the rescuer's subjective perceived exertion during chest compressions, namely through the Borg 
Scale (Ock et al., 2011). However, other studies have assessed fatigue through physiological parameters, such as heart rate (HR), peripheral oxygen saturation (SpO2), maximal oxygen uptake (VO2max), serum lactate level, or even the rescuer's adrenaline and noradrenaline levels before and after CPR (Trowbridge et al., 2009; Hasegawa et al., 2014; Otsuka et al., 2014; Yang et al., 2014). These latter studies demonstrate that fatigue is a relevant topic in resuscitation, and that can be analyzed using different methodologies. Knowing that chest compressions are physically demanding, the ability to perform them with quality over time can be affected by the rescuer's physical fitness, particularly muscle mass and strength (Hansen et al., 2012; Ock et al., 2011).

\section{Research questions}

Does the percentage of correct compressions performed per minute reduce over time?; Does the rescuer's heart rate, respiratory rate and peripheral oxygen saturation vary significantly over time?; Does capillary blood lactate increase during the chest compression procedure?; Is the rate of proper chest compressions positively correlated with Body Mass Index?; Is the rate of proper chest compressions positively correlated with physical fitness variables?; Is the rate of proper chest compressions correlated with lactate levels?

Table 1

\section{Study variables and protocol}

\section{Methodology}

Taking into account this issue, the study objectives and the research questions, we conducted a descriptive-correlational study. The target population of the study were nurses with experience in CPR working in the emergency room of the Bragança hospital unit of the Northeast Local Health Unit $(n=32)$, nurses of the medical emergency and resuscitation vehicle of that health unit $(n=20)$, and voluntary firefighters of Bragança with experience in out-of-hospital CPR and training in Advanced Life Support $(n=27)$. Through a non-probability snowball sampling, the final sample was composed of 38 individuals.

The field work was conducted in the simulation laboratory of the School of Health of the Polytechnic Institute of Bragança (ESS/IPB). Data were collected on Saturday mornings, so as not to interfere with the academic activities, and provide a favorable environment for simulation and research.

We used a structured sheet with the variables and the study protocol to collect the information, as shown in Table 1. In order to better understand the assessed physiological parameters, these can be grouped as follows: rescuer fatigue (lactate level, HR, respiratory rate and SpO2); physical fitness (muscle strength of the dominant hand, muscle mass of the trunk and upper limbs, and maximum compression isometric force) and anthropometric variables (weight, height and BMI).

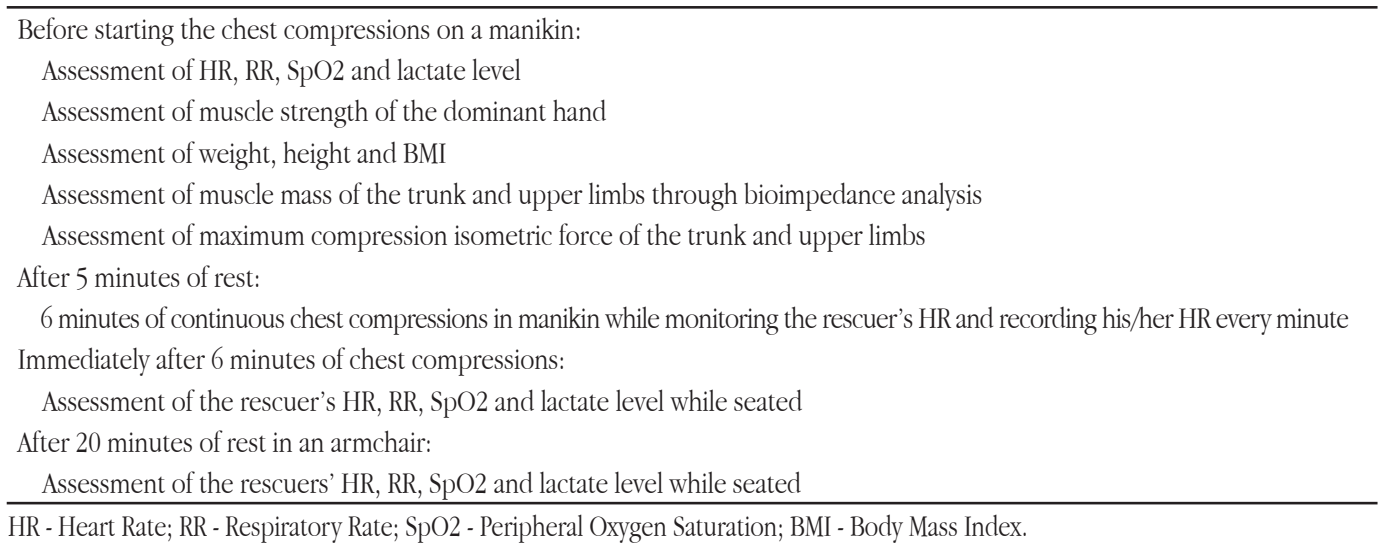


The analysis of the rescuer's blood lactate level through capillary puncture using the Accutrend Plus system was performed before and after the chest compressions and 20 minutes after rest. Muscle strength of the dominant hand was assessed using the Jamar dynamometer, registering the highest score obtained in three assessments, with interpolated rest periods. We used the Tanita BC-545 bioimpedance scale to extract data about the rescuer's weight, and muscle mass of the trunk and upper limbs. The maximum compression isometric force of the trunk and upper limbs was assessed using a

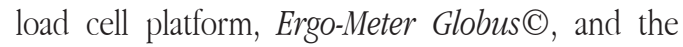
corresponding software. Height was measured using a classic stadiometer. The rescuer's HR was assessed every minute during the 6-minute period of chest compressions through cardiac monitoring. After 6 minutes of chest compressions, the rescuer rested for 20 minutes in an armchair with arm and foot rests.

Chest compressions were performed according to the 2010 CPR guidelines (Nolan et al., 2010) in the manikin Resusci Anne with the Laerdal PC Skill Reporting System and the percentage of correct compressions (PCC) per minute was automatically obtained via its outputs and reports.

The rescuer's performance was assessed based on the PCC over the 6-minute period, during which the used equipment calculates this percentage taking into account the positioning of the hands, the mean depth of the compressions and chest extension. The manikin was placed on the floor and the rescuer performed the compressions on his/her knees in a fitness mattress. During the period of 6 minutes, the participants did not receive any visual or auditory feedback on the quality of the chest compressions being performed.

The information obtained was introduced in a SPSS (Statistical Package for the Social Sciences) file. The research questions were analyzed using non-parametric tests, without being necessary to verify the hypotheses of normality. A two-tailed $p$-value $<.05$ was considered to be statistically significant.

We asked the Executive Board of the ESS/IPB for permission to use the laboratory and equipment, which was granted. Participants were informed about the research objectives and protocol and signed an informed consent form.

\section{Results}

The sample included nurses $(n=26)$ and firefighters $(n=12)$. The participants had a mean age of 33 years, were mostly men (68.4\%), and had approximately 9 years of experience in in-hospital or out-of-hospital resuscitation (Table 2).

Table 2

Participants' sociodemographic and anthropometric characteristics

\begin{tabular}{lcc}
\hline & $n(\%)$ & $\mathrm{M} \pm \mathrm{SD}$ \\
\hline Age (years) & 38 & $33.1 \pm 8.6$ \\
Gender & & \\
$\quad$ Female & $12(31.6)$ & \\
$\quad$ Male & $26(68.4)$ & \\
Occupation & & \\
$\quad$ Nursing & $26(68.4 \%)$ & \\
Firefighter & $12(31.6 \%)$ & $168.2 \pm 7.0$ \\
Height $(\mathrm{cm})$ & 38 & $75.4 \pm 20.4$ \\
Weight $(\mathrm{Kg})$ & 38 & $26.4 \pm 5.6$ \\
BMI $\left(\mathrm{kg} / \mathrm{m}^{2}\right)$ & 38 & $8.9 \pm 7.2$ \\
Experience in reanimation (years) & 38 & \\
\hline
\end{tabular}

M - Mean; SD - Standard Deviation.

In the first minute, we obtained a mean percentage of correct compressions of $76.3 \%$. This rate decreased to $39.5 \%$ at the end of the sixth minute. We found a statistically significant reduction of the PCC over the period of 6 minutes using a Wilcoxon Test, as shown in Figure 1. 


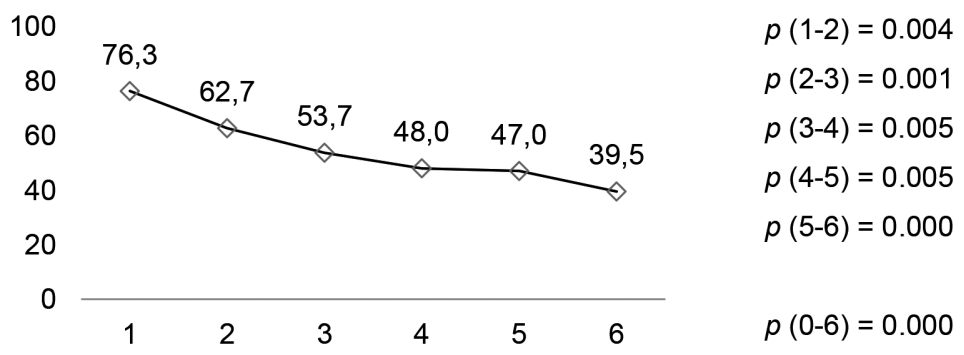

Figure 1. Mean percentage of correct compressions performed during the 6-minute period.

The rescuer's HR increased significantly over the of 79.4 heart beats per minute to 145.5 heart beats various moments under analysis, from a baseline value during the sixth minute, as can be seen in Table 3 .

Table 3

Rescuer's heart rate during the 6-minute period

\begin{tabular}{lc}
\hline Minutes & Rescuer's HR $(\mathrm{M} \pm \mathrm{SD})$ \\
\hline 0 (Baseline) & $79.4 \pm 10.1$ \\
1 & $135.4 \pm 17.5$ \\
2 & $140.8 \pm 17.3$ \\
3 & $143.7 \pm 19.0$ \\
4 & $144.7 \pm 19.6$ \\
5 & $144.1 \pm 19.8$ \\
6 & $145.5 \pm 20.2$ \\
\hline$p^{1}$ & .000 \\
\hline 1 - Friedman Test; HR - Heart Rate; M - Mean; SD - Standard Deviation.
\end{tabular}

Table 4 presents the baseline values of the variables used to assess fatigue after the period of 6 minutes of chest compressions and after 20 minutes of rest in an armchair. We observed that the HR, the RR and the SpO2 varied significantly over time. The baseline values of lactate level $(1.7 \pm .7 \mathrm{mmol} / \mathrm{L})$ increased exponentially after 6 minutes $(5.4 \pm 1.5 \mathrm{mmol} / \mathrm{L})$ and were still above baseline values after the rest period $(3.7 \pm 1.2 \mathrm{mmol} / \mathrm{L})$.

Table 4

Mean baseline values after 6 minutes of chest compressions and after 20 minutes of rest obtained in the variables related to the rescuer's effort

\begin{tabular}{lcccc}
\hline & $\begin{array}{c}\text { Baseline } \\
(\mathrm{M} \pm \mathrm{SD})\end{array}$ & $\begin{array}{c}\text { After 6min of CC } \\
(\mathrm{M} \pm \mathrm{SD})\end{array}$ & $\begin{array}{c}\text { After 20min rest } \\
(\mathrm{M} \pm \mathrm{SD})\end{array}$ & $p^{1}$ \\
\hline HR $(\mathrm{bpm})$ & $79.4 \pm 10.1$ & $128.3 \pm 19.8$ & $84.5 \pm 10.9$ & 0.000 \\
RR $(\mathrm{cycles} / \mathrm{m})$ & $21.6 \pm 2.7$ & $31.1 \pm 4.5$ & $21.3 \pm 2.4$ & 0.000 \\
SpO2 $(\%)$ & $98.0 \pm 0.9$ & $97.6 \pm 0.5$ & $97.7 \pm 0.7$ & 0.038 \\
Lactate $(\mathrm{mmol} / \mathrm{L})$ & $1.7 \pm 0.7$ & $5.4 \pm 1.5$ & $3.7 \pm 1.2$ & 0.000 \\
\hline
\end{tabular}

1 - Friedman test; M - Mean; SD - Standard Deviation; CC - Chest Compressions; HR - Heart Rate; bpm - beats per minute; RR - Respiratory Rate; SpO2 - Peripheral Oxygen Saturation; mmol/L - millimole/liter.

We found a positive association between the different moments of assessment of the PCC (Table 5). With the exception of the first minute, we also found moderate positive correlations between PCC and the rescuer's BMI. The rescuer's experience and age were not correlated with PCC. 
Table 5

Spearman's correlation coefficients between the Percentage of Correct Compressions per minute and the sociodemographic and anthropometric variables

\begin{tabular}{|c|c|c|c|c|c|c|c|c|c|}
\hline & PCC $1^{\text {st }}$ & PCC $2^{\text {nd }}$ & PCC $3^{\text {rd }}$ & PCC $4^{\text {th }}$ & $\mathrm{PCC} 5^{\text {th }}$ & PCC $6^{\text {th }}$ & Age & ER & BMI \\
\hline PCC $1^{\text {st }}$ & 1 & & & & & & & & \\
\hline PCC $2^{\text {nd }}$ & $.57 * *$ & 1 & & & & & & & \\
\hline PCC $3^{\text {rd }}$ & $.48 * *$ & $.88^{* * *}$ & 1 & & & & & & \\
\hline PCC $4^{\text {th }}$ & $.50 * *$ & $.74 * *$ & $.86 * *$ & 1 & & & & & \\
\hline PCC $5^{\text {th }}$ & $.44^{* *}$ & $.65 * *$ & $.77 * *$ & $.80 * *$ & 1 & & & & \\
\hline PCC $6^{\text {th }}$ & $.48 * *$ & $.75^{* * *}$ & $.83^{* * *}$ & $.87^{* * *}$ & $.78^{* * *}$ & 1 & & & \\
\hline Age & .02 & -.17 & -.08 & .02 & .15 & -.07 & 1 & & \\
\hline ER & .29 & -.03 & -.01 & .10 & .26 & .06 & $.76 * *$ & 1 & \\
\hline BMI & .27 & $.34 *$ & $.35^{*}$ & $.33^{*}$ & $.38 *$ & $34^{*}$ & .21 & $.38 *$ & 1 \\
\hline
\end{tabular}

PCC - Percentage of Correct Compressions; ER - Experience in Reanimation; BMI - Body Mass Index; * Significant correlation at .05 (twotailed); **Significant correlation at .01 (two-tailed).

The rescuer's handgrip strength of the dominant hand was only moderately correlated with the PCC in the first and fourth minutes. The maximum compression isometric force was correlated with the
PCC within the 6-minute period. Similarly, the higher the muscle mass of the trunk and upper limbs, the higher the PCC from the first to the sixth minute.

Table 6

Spearman's correlation coefficients between the Percentage of Correct Compressions per minute and the physical fitness variables

\begin{tabular}{|c|c|c|c|c|c|c|c|c|c|}
\hline & PCC $1^{\text {st }}$ & PCC $2^{\text {nd }}$ & $\operatorname{PCC} 3^{\text {rd }}$ & PCC $4^{\text {th }}$ & $\operatorname{PCC} 5^{\text {th }}$ & $\operatorname{PCC} 6^{\text {th }}$ & DHS & $\mathrm{MCIF}$ & MM \\
\hline PCC $1^{\text {st }}$ & 1 & & & & & & & & \\
\hline $\operatorname{PCC} 2^{\text {nd }}$ & $.57 * *$ & 1 & & & & & & & \\
\hline $\operatorname{PCC} 3^{\text {rd }}$ & $.48 * *$ & $.88^{* *}$ & 1 & & & & & & \\
\hline PCC $4^{\text {th }}$ & $.50 * *$ & $.74 * *$ & $.86 * *$ & 1 & & & & & \\
\hline $\operatorname{PCC} 5^{\text {th }}$ & $.44 * *$ & $.65^{* *}$ & $.77 * *$ & $.80 * *$ & 1 & & & & \\
\hline PCC $6^{\text {th }}$ & $.48 * *$ & $.75 * *$ & $.83 * *$ & $.87^{* * *}$ & $.78 * *$ & 1 & & & \\
\hline DHS & $.39 *$ & .27 & .17 & $.32 *$ & .21 & .27 & 1 & & \\
\hline MCIF & $.58 * *$ & $.47 * *$ & $.45 * *$ & $.57 * *$ & $.65 * *$ & $.59 * *$ & $.65^{* *}$ & 1 & \\
\hline MM & $.52 * *$ & $.43 * *$ & $.38^{*}$ & $.45 * *$ & $.40 *$ & $.47^{* * *}$ & $.65 * *$ & $.84 * *$ & 1 \\
\hline
\end{tabular}

PCC - Percentage of Correct Compressions; DHS - Dominant Hand Strength; MCIF - Maximum Compression Isometric Force; MM Muscle Mass (of the trunk and upper limbs); *Significant correlation at .05 (two-tailed); **Significant correlation at .01 (two-tailed).

According to Table 7 , the lactate levels were not correlated with the PCC during the period of 6 minutes. We also found no significant association between the rescuer's HR or SpO2 and the PCC. At the end of the 6-minute heart massage, the higher the rescuers' $H R$, the higher the lactate levels. 
Table 7

Spearman's correlation coefficients between the Percentage of Correct Compressions per minute and the variables of Heart Rate, Peripheral Oxygen Saturation and Lactate after a resuscitation period of 6 minutes

\begin{tabular}{|c|c|c|c|c|c|c|c|c|c|}
\hline & PCC $1^{\text {st }}$ & PCC 2 $2^{\text {nd }}$ & $\mathrm{PCC}_{3}^{\text {rd }}$ & PCC $4^{\text {th }}$ & PCC $5^{\text {th }}$ & PCC $6^{\text {th }}$ & $\mathrm{HR}^{1}$ & $\mathrm{SpO}^{1}$ & Lact $^{1}$ \\
\hline PCC $1^{\text {st }}$ & 1 & & & & & & & & \\
\hline PCC $2^{\text {nd }}$ & $.57^{* *}$ & 1 & & & & & & & \\
\hline PCC $3^{\text {rd }}$ & $.48^{* * *}$ & $.88^{* * *}$ & 1 & & & & & & \\
\hline PCC $4^{\circ}$ & $.50^{* * *}$ & $.74 * *$ & $.86 * *$ & 1 & & & & & \\
\hline PCC $5^{\circ}$ & $.44^{* * *}$ & $.65 * *$ & $.77 * *$ & $.80^{* * *}$ & 1 & & & & \\
\hline PCC $6^{\circ}$ & $.48^{* * *}$ & $.75 * *$ & $.83^{* * *}$ & $.87^{* * *}$ & $.78^{* * *}$ & 1 & & & \\
\hline $\mathrm{HR}^{1}$ & .23 & 16 & .24 & .21 & .18 & .26 & 1 & & \\
\hline $\mathrm{SpO}^{1}{ }^{1}$ & -.05 & -.09 & -.05 & .11 & -.08 & .17 & .13 & 1 & \\
\hline $\mathrm{Lact}^{1}$ & .15 & .26 & .13 & .14 & -.02 & .16 & $.44^{* *}$ & -.04 & 1 \\
\hline
\end{tabular}

HR - Heart Rate; SpO2 - Peripheral Oxygen Saturation; Lact - Lactate; *Significant correlation at .05 (two-tailed); ** Significant correlation at .01 (two-tailed); 1- Based on the results obtained after 6 minutes of chest compressions.

\section{Discussion}

The results show that the quality of chest compressions on a manikin declined progressively over the period of 6 minutes. The first minute was the only moment when we observed a PCC higher than $70 \%$, which is considered necessary for an effective circulatory support to a victim in CPR (Ochoa et al., 1998). Other studies found similar results (Otsuka et al., 2014; Hasegawa et al., 2014; Ock et al., 2011). For example, Ock et al. (2011) found a decrease in the percentage of correct compressions ranging from $78.8 \%$ in the first minute to $28.0 \%$ in the fifth minute. The quality of chest compressions reduces so much from the first minute that some authors recommend that rescuers be replaced every minute, especially in the case of continuous compressions, for example, in patients with an endotracheal tube (Nishiyama et al., 2010). Our results corroborate this recommendation. In relation to the effort and fatigue variables, we found that the rescuer's $\mathrm{HR}, \mathrm{RR}, \mathrm{SpO} 2$ and lactate level varied significantly in the three moments under analysis. In a comparison between two groups of rescuers following the 2005 and 2010 guidelines, Yang et al. (2014) concluded that the 2010 guidelines, by recommending a chest compression of at least $5 \mathrm{~cm}$, require an increased effort from rescuers, leading to increased HR and lactate levels. The authors found a baseline lactate level of $1.4 \mathrm{mmol} / \mathrm{L}( \pm .5 \mathrm{mmol} / \mathrm{L})$ which increased to $3.7 \mathrm{mmol} / \mathrm{L}( \pm 1.0 \mathrm{mmol} / \mathrm{L})$ after a resuscitation period of 8 minutes. Another study found a baseline value of $1.3 \mathrm{mmol} / \mathrm{L}( \pm .6 \mathrm{mmol} / \mathrm{L})$ which increased to $3.3 \mathrm{mmol} / \mathrm{L}( \pm 1.9 \mathrm{mmol} / \mathrm{L})$ after a period of 7 minutes (Otsuka et al., 2014).

One of the most important findings of our study is the fact that the lactate level assessed after 20 minutes of rest $(3.7 \pm 1.2 \mathrm{mmol} / \mathrm{L})$ remained significantly above the baseline values of the sample and very similar to the anaerobic threshold of $4 \mathrm{mmol} / \mathrm{L}$ found in the literature (Heck et al., 1985).

In our study, the BMI values were positively correlated with the PCC, which is similar to the results obtained by Russo et al. (2011). Another study found that low-weight rescuers had a lower PCC (López González, Sánchez López, Rovira Gil, Ferrer López, \& Martínez Vizcaíno, 2014). A study conducted with a sample of 102 trained nursing students reported that BMI was the greatest predictor for the quality of chest compressions (Roh \& Lim, 2013). In a sample of 72 experienced physicians and nurses, Sánchez et al. (2015) concluded that the decreasing quality of chest compressions was associated with a BMI $<23 \mathrm{~kg} / \mathrm{m}^{2}$. We observed significant correlations, during the 6-minute period under analysis, in relation to the PCC performed, which indicates that better initial performances lead to better results throughout the different moments assessed.

Physical fitness influenced significantly the quality of the heart massage in the participants of our study. Many studies found similar results while analyzing different components of physical fitness, such as cardiorespiratory fitness and muscle strength (Ock et al., 2011; Otsuka et al., 2014; Russo et al., 2011). However, we have no knowledge of any study 
using bioimpedance to study the influence of body composition in the quality of the heart massage. In this regard, we found a positive, although weak to moderate, correlation between the muscle mass of the upper limbs and trunk and the quality of the chest compressions during the 6-minute period under analysis.

In relation to the last research question, the lactate levels were not significantly correlated with the PCC during the 6-minute period. Further research is needed to explore this issue.

In addition to having used a limited sample, which is partly explained by the applied sampling procedure, this study has other limitations. The first limitation is the fact that it was conducted in a simulated scenario, and not in actual clinical settings. The second limitation relates to the time period that we established for continuous compressions (6 minutes), which poses some difficulties in terms of comparing our results with other studies, since similar studies used different time ranges (2-12 minutes). Finally, although we only used three adhesive gel electrodes, the HR monitoring may have limited the rescuers' movements of compression/release.

\section{Conclusion}

Based on the research objectives and questions, we concluded that the quality of the compressions decreased significantly during the 6-minute period. The BMI and the components of physical fitness, handgrip strength, and muscle strength and mass of the trunk and upper limbs were the variables that best explained the decrease of the PCC.

We recommend that further studies be conducted in real-life settings or using high-fidelity simulators to analyze the physiological effects of the rescuer's fatigue and their impact on CPR.

In terms of the implications for clinical practice, our results on the lactate levels suggest that the professionals performing chest compressions in very prolonged CPRs may not fully recover from the muscle fatigue after resting for 20 minutes. In this sense, their immediate participation in new CPR maneuvers should be considered with caution. Another implication for practice is the recommendation that emergency care professionals should pay attention to their physical fitness, particularly muscle strength and mass of upper limbs. Since these variables, along with the BMI, were found to be predictors for the quality of the heart massage, our results suggest that the initial chest compressions (the first minutes of CPR) should be performed by the professionals who are in best shape.

Taking into account the decreasing PCC found after the first minute, we also suggest a greater distribution of the pressure sensors currently available on the market. After being placed on the victim's chest, these sensors provide feedback to the professionals on the quality of the heart massage being performed so as to improve the outcomes of these compressions.

\section{References}

Berdowski, J., Berg, R. A., Tijssen, J. G., \& Koster, R. W. (2010). Global incidences of out-of-hospital cardiac arrest and survival rates: Systematic review of 67 prospective studies. Resuscitation, 81(11), 1479-1487. doi:10.1016/j. resuscitation.2010.08.006

Bjørshol, C. A., Sunde, K., Myklebust, H., Assmus, J., \& Søreide, E. (2011). Decay in chest compression quality due to fatigue is rare during prolonged advanced life support in a manikin model. Scandinavian Journal of Trauma Resuscitation and Emergency Medicine, 9, 19-46. doi: 10.1186/1757-7241-1946

Go, A. S., Mozaffarian, D., Roger, V. L., Benjamin, E. J., Berry, J. D., Borden, W. B., ... Subcommittee, American Heart Association Statistics Committee and Stroke Statistics. (2013). Heart disease and stroke statistics: 2013 update: A report from the American Heart Association. Circulation, 127(1), e6-e245. doi:10.1161/CIR.0b013e31828124ad

Hansen, D., Vranckx, P., Broekmans, T., Eijnde, B. O., Beckers, W., Vandekerckhove, P., ... Dendale, P. (2012). Physical fitness affects the quality of single operator cardiocerebral resuscitation in healthcare professionals. European Journal Emergency Medicine, 19(1), 28-34. doi:10.1097/ MEJ.0b013e328347a2aa

Hasegawa, T., Daikoku, R., Saito, S., \& Saito, Y. (2014). Relationship between weight of rescuer and quality of chest compression during cardiopulmonary resuscitation. Journal of Physiological Anthropology, 33, 16. doi:10.1186/18806805-33-16

Heck, H., Mader, A., Hess, G., Mücke, S., Müller, R., \& Hollmann, W. (1985). Justification of the 4-mmol/ lactate threshold. International Journal of Sports Medicine, 6(3), 117-130. doi:10.1055/s-2008-1025824

López González, Á., Sánchez López, M., Rovira Gil, E., Ferrer López, V., \& Martínez Vizcaíno, V. (2014). Influencia del índice de masa corporal y la forma física de jóvenes universitarios en 
la capacidad de realizar compresiones torácicas externas de calidad sobre maniquí. Emergencias, 26, 195-201.

Nishiyama, C., Iwami, T., Kawamura, T., Ando, M., Yonemoto, N., Hiraide, A., \& Nonogi, H. (2010). Quality of chest compressions during continuous CPR; comparison between chest compression: Only CPR and conventional CPR. Resuscitation, 81(9), 1152-1155. doi:10.1016/j. resuscitation.2010.05.008

Nolan, J. P., Soar, J., Zideman, D. A., Biarent, D., Bossaert, L. L., Deakin, C., ... European Resuscitation Council. (2010). European resuscitation council guidelines for resuscitation 2010 section 1: Executive summary. Resuscitation, 81(10), 1219-1276. doi:10.1016/j.resuscitation.2010.08.021

Ochoa, F. J., Ramalle-Gómara, E., Lisa, V., \& Saralegui, I. (1998). The effect of rescuer fatigue on the quality of chest compressions. Resuscitation, 37(3), 149-152. doi:10.1016/ S0300-9572(98)00057-4

Ock, S. M., Kim, Y. M., Chung, J., \& Kim, S. H. (2011). Influence of physical fitness on the performance of 5-minute continuous chest compression. European Journal Emergency Medicine, 18(5), 251-256. doi:10.1097/MEJ.0b013e328345340f

Otsuka, Y., Kasaoka, S., Oda, Y., Nakahara, T., Tanaka, R., Todani, M., ... Tsuruta, R. (2014). Effects of uninterrupted chest compressions on the rescuer's physical condition.The American Journal Emergency Medicine, 32(8), 909-912. doi:10.1016/j.ajem.2014.05.008

Ramos, R., Ascenção, C., \& Oliveira, M. S. d. (2013). Presumed cardiac out of hospital cardiac arrest in Portugal: Five year report. Resuscitation, 84(sup.1), S9. doi:http://dx.doi. org/10.1016/j.resuscitation.2013.08.036

Roh, Y., \& Lim, E. (2013). Factors influencing quality of chest compression depth in nursing students. International
Journal of Nursing Practice, 19(6), 591-595. doi: 10.1111/ ijn.12105

Russo, S. G., Neumann, P., Reinhardt, S., Timmermann, A., Niklas, A., Quintel, M., \& Eich, C. B. (2011). Impact of physical fitness and biometric data on the quality of external chest compression: A randomised, crossover trial. BMC Emergency Medicine, 11, 20. doi:10.1186/1471-227X-11-20

Shin, J., Hwang, S. Y., Lee, H. J., Park, C. J., Kim, Y. J., Son, Y. J., . . . Hong, S. G. (2014). Comparison of CPR quality and rescuer fatigue between standard 30:2 CPR and chest compression-only CPR: A randomized crossover manikin trial. Scandinavian Journal of Trauma Resuscitation and Emergency Medicine, 22(59). doi:10.1186/s13049-014-0059-x

Sánchez, B., Algarte, R., Piacentini, E., Trenado, J., Romay, E., Cerdà, M., ... Quintana, S. (2015). Low compliance with the 2 minutes of uninterrupted chest compressions recommended in the 2010 international resuscitation guidelines. Journal of Critical Care, 30(4), 711-714. doi:10.1016/j.jcrc.2015.03.001

Taw, R. L. (1991). Dr. Friedrich Maass: 100th anniversary of "new" CPR. Clinical Cardiology, 14(12), 1000-1002. doi: 10.1002/ clc. 4960141211

Trowbridge, C., Parekh, J. N., Ricard, M. D., Potts, J., Patrickson, W. C., \& Cason, C. L. (2009). A randomized cross-over study of the quality of cardiopulmonary resuscitation among females performing 30:2 and hands-only cardiopulmonary resuscitation. BMC Nursing, 8(6). doi:10.1186/1472-6955-8-6

Yang, Z., Li, H., Yu, T., Chen, C., Xu, J., Chu, Y., ... Huang, Z. (2014). Quality of chest compressions during compressiononly CPR: A comparative analysis following the 2005 and 2010 American Heart Association guidelines. The American Journal of Emergency Medicine, 32(1), 50-54. doi:10.1016/j. ajem.2013.09.043 
